\title{
A Spectral, Optical, Microscopic Study, Synthesis and Characterization of PVC Films Containing Schiff Base Complexes
}

\author{
Emad Yousif $^{1 *} \quad$ Noora Asaad ${ }^{1} \quad$ Dina S. Ahmed ${ }^{2} \quad$ Salam A. Mohammed $^{3}$ \\ Ali H. Jawad ${ }^{4}$
}

Received 25/6/2018, Accepted 29/1/2019, Published 11/3/2019

This work is licensed under a Creative Commons Attribution 4.0 International License.

\begin{abstract}
:
In this work, synthesis of conducting polymeric films namely, PVC thin films was carried out containing Schiff base (L) with $\mathrm{Cu}^{2+}, \mathrm{Cr}^{3+}, \mathrm{Ni}^{2+}, \mathrm{Co}^{2+}$, in addition to inspecting the possibilities of measuring energy gap values of PVC-L-M with variety metal ions. These new polymeric films (PVC-L-M) were characterized by FTIR spectrophotometry, energy gap and surface morphology. The optical data recorded that the band gap values are influenced by the type of metals. All modified films have a red shift in optical properties in the ultraviolet region. The PVC-L-Co(II) was the lowest value of the optical band gap, $3.1 \mathrm{eV}$.
\end{abstract}

Keywords: Conducting polymers, Metal complexes, Optical properties, PVC, Schiff Base.

\section{Introduction:}

Semiconductor materials with massive range have various features. Utilizing these features makes it reasonable to form e.g. LEDs emitting light through a huge extent of memristor instruments or wavelengths (1). Photon established techniques (reaction measurements or absorption) can provide optical band gap data e.g. by adjust a Tauc plot (2), but probe mostly much thicker layers. Photoemission experiments can be utilized to get band gap data. Here the separation of a sharp core level with the onset of improved intensity of the background can be seen as a band gap fingerprint (see e.g. 3). The electronic and optical behavior of semiconductors is determined by two essential properties namely refractive index and energy gap. Material refractive index is reduced with energy gap and therefore, these two essential quantities of a material are believed to have certain correlation. There were many attempts to discover appropriate relationship, both semi empirical and empirical, between the refractive index and semiconductors energy gap $(4,5,6,7)$.

${ }^{1}$ Department of Chemistry, College of Science, AlNahrain University, Baghdad 64021, Iraq ${ }^{2}$ Department of Medical Instrumentation Engineering, Al-Mansour University College, Baghdad 64021, Iraq

3 Department of Chemical and Petrochemical Engineering, College of Engineering and Architecture, University of Nizwa, 616, Nizwa, Oman

${ }^{4}$ Faculty of Applied Sciences, Universiti Teknologi MARA, Shah Alam, Selangor, Malaysia

* Corresponding author: emadayousif@gmail.com
The physiological importance of oxygen donor in the organic compounds increasing the active role acted by coordinating certain metal ions to utilize in studying the structural aspects and synthesizing metal complexes with some sulphur, nitrogen and oxygen donor ligands (8-10). The aim of this work is to study transition metals influence on the optical, electrical properties and surface morphology of the novel materials.

\section{Materials and Methods}

From Sigma-Aldrich (Gillingham, UK), $\mathrm{CuCl}_{2} \cdot 2 \mathrm{H}_{2} \mathrm{O}, \mathrm{NiCl}_{2} \cdot 6 \mathrm{H}_{2} \mathrm{O}, \mathrm{CoCl}_{2}, \mathrm{CrCl}_{3}$ and the solvent were purchased and utilized without any purification. $K$ value of $\mathrm{PVC}=67$, polymerization degree $=800$ ) was acquired from Petkim (Istanbul, Turkey).

\section{Instrumentation}

A Shimadzu 8400 Spectrophotometer (Shimadzu Cooperation, Kyoto, Japan) was used to record the FTIR spectra (4000-400 $\left.\mathrm{cm}^{-1}\right)$ using the $\mathrm{KBr}$ disk technique. A Bruker DRX400 NMR Spectrometer (Bruker, Zürich, Switzerland) $400 \mathrm{MHz}$ was utilized to record ${ }^{1} \mathrm{H}-\mathrm{NMR}$ spectra in DMSO-d6 to record the changes in energy gap values for polymeric films measured by diffuse reflectance UV-Vis Spectroscopy. The surface morphology of polymeric films was recorded on Meiji Techno Microscope (Meiji Techno, Tokyo, Japan). 


\section{Schiff base Preparation}

Schiff base Fig. 1 was prepared as previously reported (11), from reaction of biphenyl-3,3',4,4'tetraamine and 3-hydroxybezaldehyde with glacial acetic acid as catalyst.

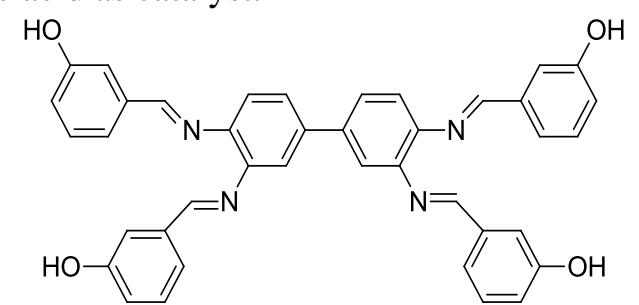

Figure 1. Structure of Schiff base (L).

\section{Synthesis of PVC -Ligand}

0.05 mole of Schiff base (L) was added to solution of $0.1 \mathrm{~g}$ PVC in $20 \mathrm{~mL}$ THF, the mixture was refluxed for 3 hours. Hot mixture was cast into petri dish. A white precipitate was formed after refluxing. The modified polymer (PVC-L) film was dried under vacuum Fig. 2.

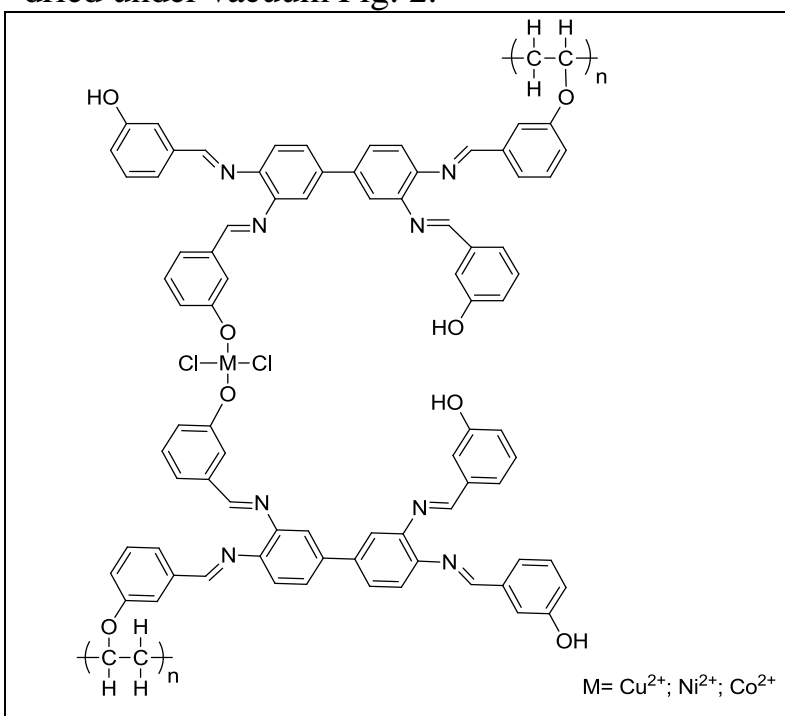

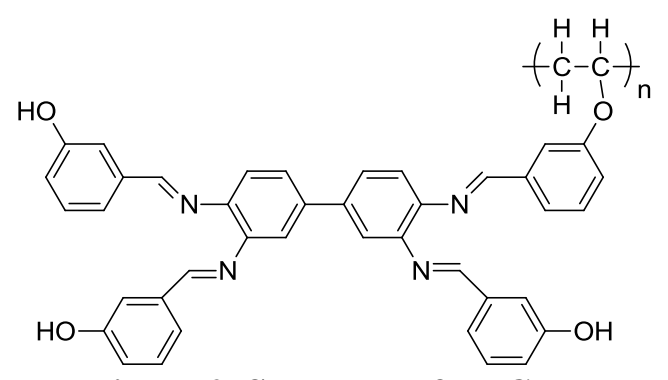

Figure 2. Structure of PVC-L.

\section{Synthesis of PVC-Ligand Complexes}

$0.3 \mathrm{gm}$ of synthesized modified polymer (PVC-L) and $0.05 \mathrm{gm}$ of metal salt were dissolved in $5 \mathrm{~mL}$ of THF. The mixture was refluxed for 3 hours in order to form the complex PVC-L-M(II) by evaporation technique for $24 \mathrm{~h}$ at room temperature. Fig. 3, shows $\mathrm{Cu}(\mathrm{II}), \mathrm{Cr}(\mathrm{III}), \mathrm{Ni}(\mathrm{II})$ and $\mathrm{Co}(\mathrm{II})$ polymeric metal chelates that have been synthesized.

\section{Figure 3. Structure of PVC-L-M.}

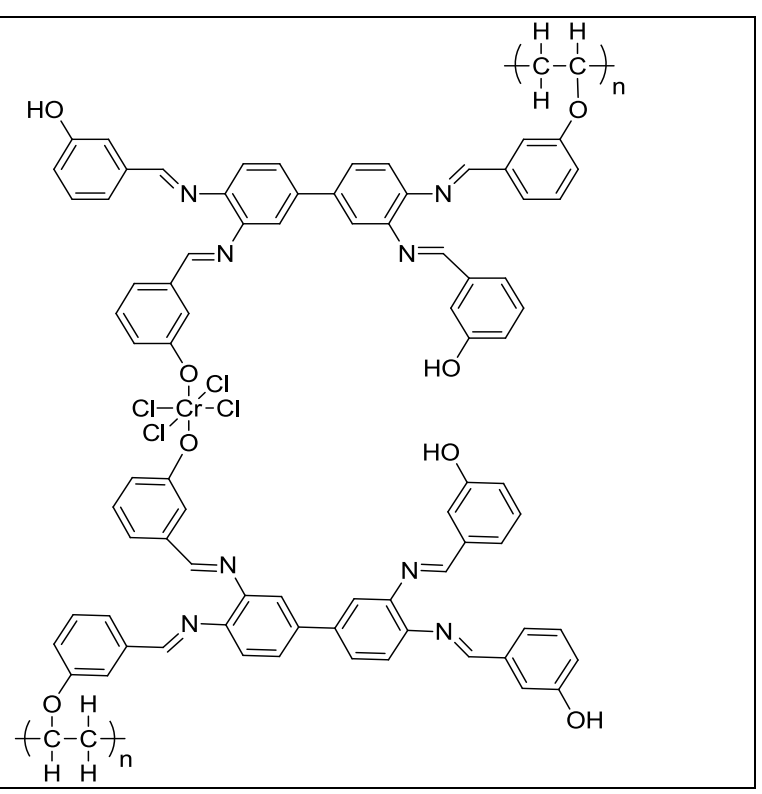

\section{PVC Films Preparation}

PVC solution $(0.5 \%$ concentration) in THF was used to synthesize $40 \mu \mathrm{m}$ thickness of polymeric films. The films were prepared by pouring the solution onto a glass plate, left to dry for a day to remove any residual of THF (12-14).

\section{Results and Discussion:}

Synthesis and Characterization of Schiff Base L

Schiff base $\mathbf{L}$ was synthesized based on literature procedures (11). Reaction of biphenyl3,3',4,4'-tetraamine and excess of 3hydroxybenzaldehyde (four mole equivalents), in the presence of glacial acetic acid as a catalyst under 4 hours reflux, gave the corresponding Schiff base $\mathbf{L}$ in $80 \%$ yields (Scheme 1).

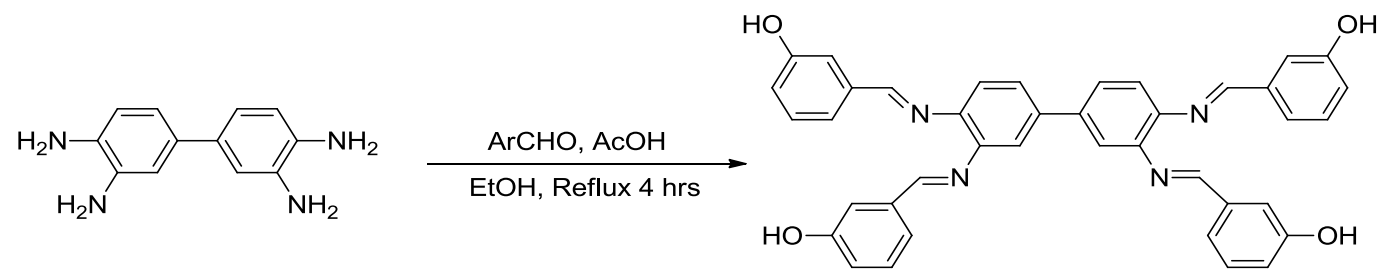

Scheme 1. Synthesis of Schiff base $L$. 
The FTIR spectrum of $\mathbf{L}$ shows absorption band at $1600 \mathrm{~cm}^{-1}$ that, due to $\mathrm{C}=\mathrm{N}$ bond, can also denote the absence of $\mathrm{NH}_{2}$ and $\mathrm{C}=\mathrm{O}$ groups absorptions which belong to ammine and aldehyde groups, respectively as shown in Fig. 4.

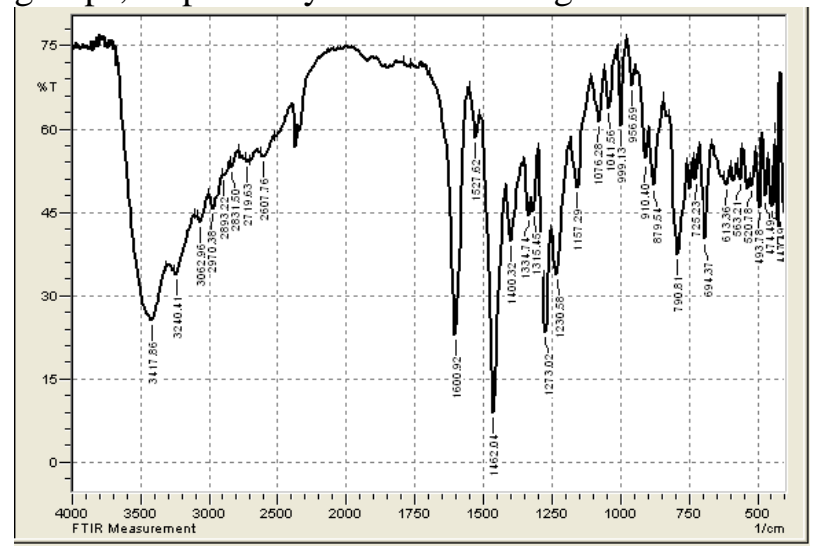

Figure 4. FTIR spectrum of Schiff base $L$.

Table 1 and Fig. 5 show the nuclear magnetic resonance spectral data for $\mathbf{L}$. It can be seen that the singlet signals that resonate at the 8.01 ppm region are attributed to the azomethine protons. Moreover, the aromatic protons with chemical shifts and expected multiplicity can be noticed (11).

Table 1. Spectral data of ${ }^{1} \mathrm{H}-\mathrm{NMR}$ for Schiff base L.

\begin{tabular}{c} 
(400 MHz: DMSO-d6, $\delta$, ppm, $\boldsymbol{J}$ in Hz) \\
\hline $8.08(\mathrm{~s}$, exch., $4 \mathrm{H}, \mathrm{OH}), 8.01(\mathrm{~s}, 4 \mathrm{H}, \mathrm{CH}), 7.63(\mathrm{~s}, 2 \mathrm{H}, \mathrm{Ar})$ \\
$7.53(\mathrm{~d}, J=8.1 \mathrm{~Hz}, 4 \mathrm{H}, \mathrm{Ar}), 7.48(\mathrm{~d}, J=8.5 \mathrm{~Hz}, 2 \mathrm{H}, \mathrm{Ar}), 7.48$ \\
$(\mathrm{~s}, 4 \mathrm{H}, \mathrm{Ar}), 7.35(\mathrm{~d}, J=8.5 \mathrm{~Hz}, 2 \mathrm{H}, \mathrm{Ar}), 7.18(\mathrm{t}, J=8.1 \mathrm{~Hz}, 4$ \\
H, Ar), $6.95(\mathrm{~d}, J=8.1 \mathrm{~Hz}, 4 \mathrm{H}, \mathrm{Ar})$
\end{tabular}

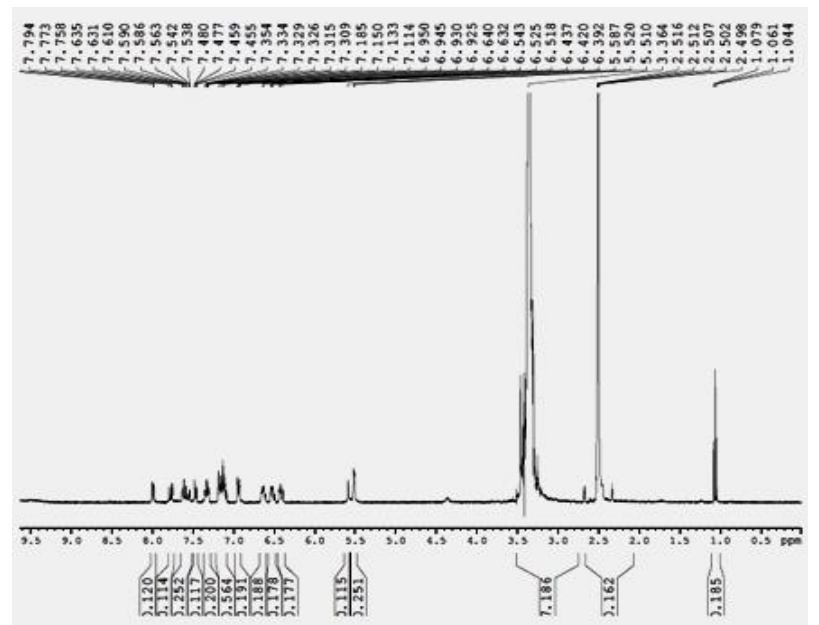

Figure 5. ${ }^{1}$ HNMR spectrum of Schiff base $\mathbf{L}$. Characterization of PVC films

The modified polymers structure was confirmed by FTIR spectroscopy, energy gap and microscope techniques. The modification of PVC films with various metals were confirmed by FTIR spectroscopy. Table 2 shows vibration bands of C$\mathrm{O}, \mathrm{M}-\mathrm{O}$ and $\mathrm{C}-\mathrm{Cl}$. Furthermore, in PVC-L (the modified polymer) spectrum can record a strong band at $v(694) \mathrm{cm}^{-1}$. This band is due to the $v(\mathrm{C}$ $\mathrm{Cl})$ band which is unlike the unmodified PVC $v$ (616) $\mathrm{cm}^{-1}$.

Table 2. FTIR bands of modified PVC films.

\begin{tabular}{cccccc}
\hline Film & C-O & C=N & $\boldsymbol{v}$ (M-O) & $\boldsymbol{v}(\mathbf{M}-\mathbf{N})$ & $\boldsymbol{v}(\mathbf{C}-\mathbf{C l})$ \\
\hline PVC-L & 1251 & 1593 & $\ldots$ & $\ldots$ & 694 \\
PVC-L- & 1247 & 1611 & 546 & 456 & 689 \\
Cu(II) & & & & & \\
$\begin{array}{c}\text { PVC-L- } \\
\text { Cr(III) }\end{array}$ & 1249 & 1616 & 540 & 491 & 670 \\
$\begin{array}{c}\text { PVC-L- } \\
\text { Ni(II) }\end{array}$ & 1250 & 1593 & 535 & 451 & 691 \\
$\begin{array}{c}\text { PVC-L- } \\
\text { Co(II) }\end{array}$ & 1251 & 1593 & 538 & 430 & 694 \\
\hline
\end{tabular}

\section{Optical Properties}

The effect of metals added to the values of energy gap was shown in Table 3, Fig. 6 and 7. The values of energy gap are decreased in the trend pure PVC-L, PVC-L- Cu, PVC-L-Cr, PVC-L-Ni and PVC-L-Co.

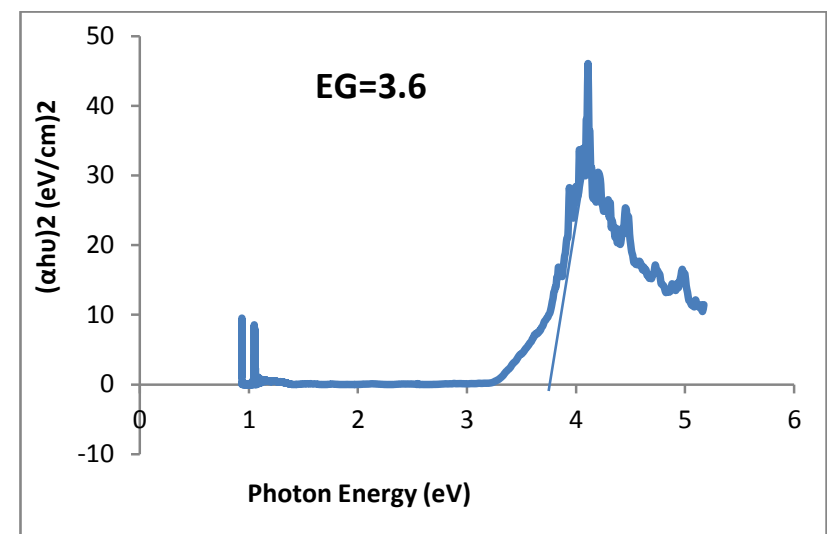

Figure 6. $(\alpha h v)^{2}$ with photon energy for PVC-LCr.

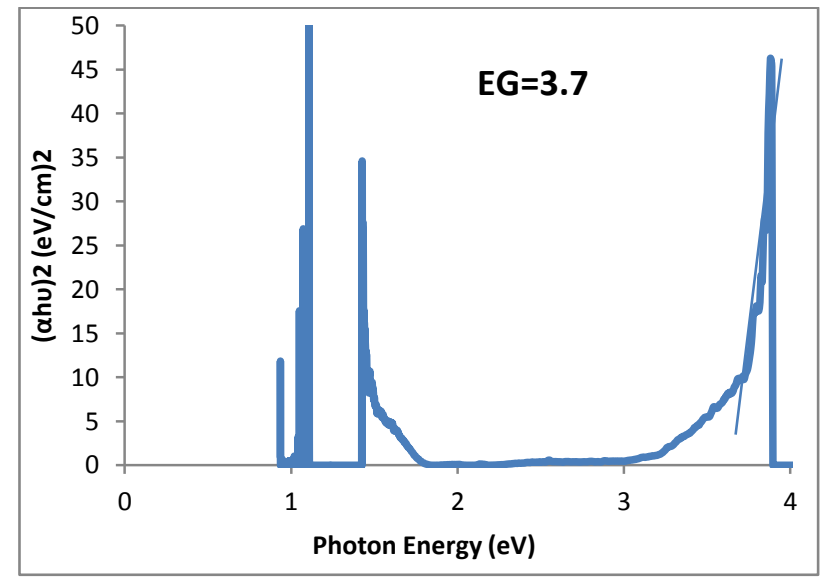

Figure 7. $(\alpha h v)^{2}$ with photon energy for PVC-LCu.

The energy gap shift could be assigned to the polarons formation in the doped films (8). The polymer-metal composites may be recognized by interaction of metal with the polar group that exists in polymeric chain. The conductivity measurement for PVC films in the additives existence following this order: PVC-L $>$ PVC-L-Cu>PVC-L-Cr $>$ PVC-LNi>PVC-L-Co. 
Table 3. Indicate the energy band gap according to the direct allowed transition.

\begin{tabular}{ll}
\hline Film & Eg $(\mathbf{e V})$ \\
\hline PVC-L & 5.39 \\
PVC-L-Cu & 3.7 \\
PVC-L-Cr & 3.6 \\
PVC-L-Ni & 3.5 \\
PVC-L-Co & 3.1 \\
\hline
\end{tabular}

\section{Surface Morphology}

Morphological characteristics of PVC-L-M have been studied as shown in Fig. 8. The polymeric thin films $(40 \mu \mathrm{m})$ thickness was determined by Digital Vernier Caliper 2610A micrometer (Vogel GmbH, Kevelaer, Germany).

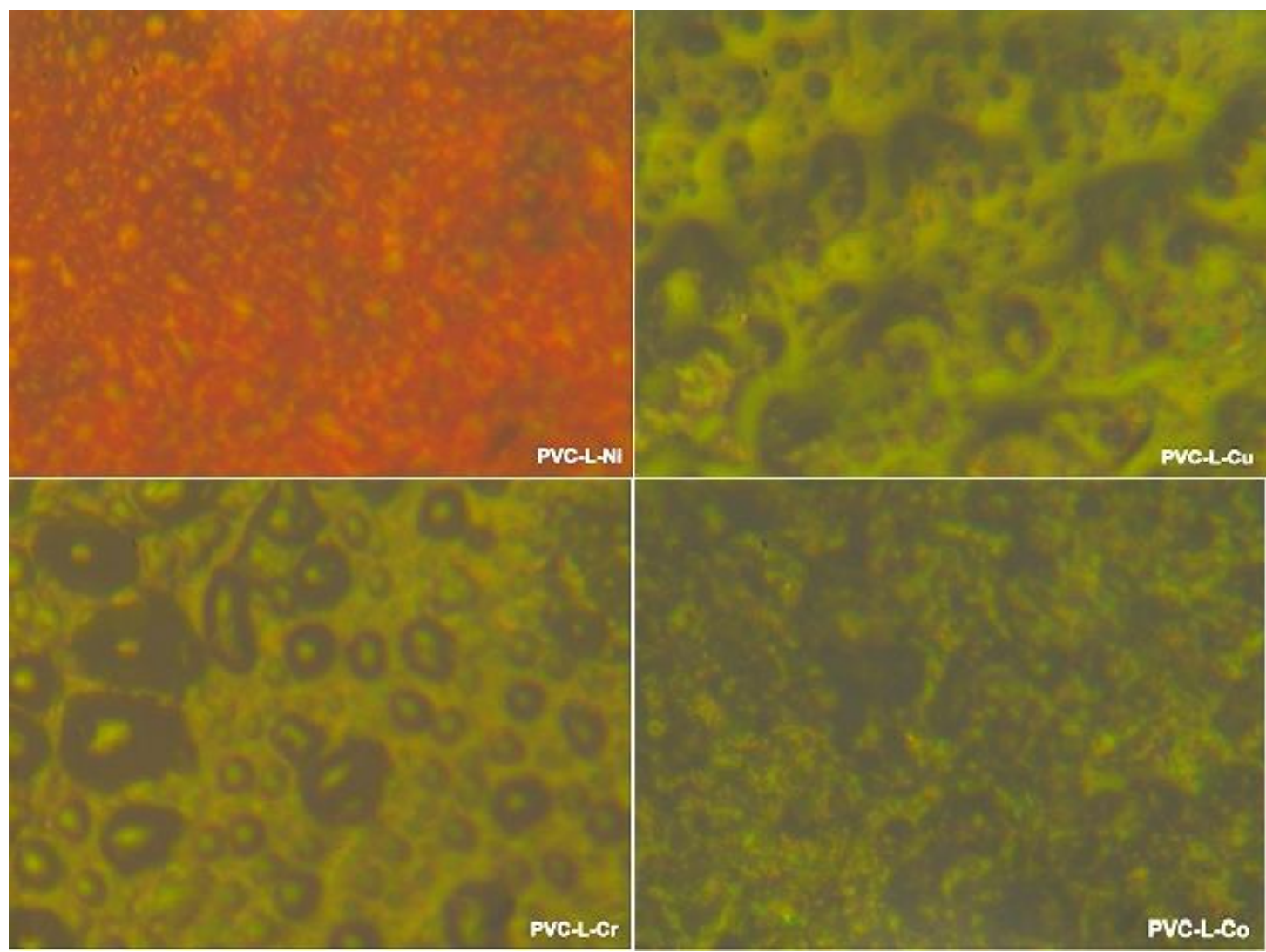

Figure 8. Microscopic images of PVC-L-M films.

The surface morphology of polymeric films was characterized by using microscope, the surface morphology confirms notifications about roughness, irregularity and defects into polymeric materials (9).

\section{Conclusion:}

The structure of Schiff base is established on the basis of its FTIR and ${ }^{1}$ HNMR spectroscopy. Each modified polymer is investigated by FTIR, diffuse reflectance UV-Vis Spectroscopy and optical microscope. The optical properties of modified PVC with different metals are investigated. The energy gap method is used to determine these properties, the energy gap values decreased as order:

PVC-L > PVC-L-Cu > PVC-L- Cr > PVC-L-Ni > PVCL-Co.

\section{Acknowledgements:}

The project was supported by Al-Nahrain University, Nizwa University and Universiti Teknologi MARA.

\section{Conflicts of Interest: None.}

\section{References}

1. Fan X, Xu P, Li YC, Zhou D, Sun Y, Nguyen MAT, et al. Controlled Exfoliation of $\mathrm{MoS}_{2}$ Crystals into Trilayer Nanosheets. J. Am. Chem. Soc. 2016;138:5143-5149.

2. Viezbicke BD, Patel S, Davis BE, Dunbar P. Birnie DP. Evaluation of the Tauc method for optical absorption edge determination: $\mathrm{ZnO}$ thin films as a model system. Physica Status Solidi, $B$. 2015;252:1700-1710.

3. Favaro M, Yang J, Nappini S, Magnano E, Toma FM, Crumlin EJ, et al. Understanding the Oxygen Evolution Reaction Mechanism on $\mathrm{CoO}_{\mathrm{x}}$ using Operando Ambient-Pressure X-ray Photoelectron Spectroscopy. J. Am. Chem. Soc. 2017;139:8960-8970.

4. Hassanien AS. Studies on dielectric properties, optoelectrical parameters and electronic polarizability of thermally evaporated amorphous $\mathrm{Cd}_{50} \mathrm{~S}_{50-\mathrm{x}} \mathrm{Se}_{\mathrm{x}}$ thin films. J. All. and Comp. 2016;671:566-578.

5. Rameshe B, Rajagopalan M, Palanivel, B. Electronic structure, structural phase stability, optical and 
thermoelectric properties of $\mathrm{Sr}_{2} \mathrm{AlM}^{\prime} \mathrm{O}_{6}\left(\mathrm{M}^{\prime}=\mathrm{Nb}\right.$ and Ta) from first principle calculations. Comput. Condense. Mat. 2015;4:13-22.

6. Villegas CEP, Rocha AR. Elucidating the Optical Properties of Novel Heterolayered Materials Based on $\mathrm{MoTe}_{2}-\mathrm{InN}$ for Photovoltaic Applications. $J$. Phys. Chem. C. 2015;119:11886-11895.

7. Singh J, Manam J. Structural and spectroscopic behaviour of $\mathrm{Eu}^{3+}$-doped $\mathrm{SrGd}_{2} \mathrm{O}_{4}$ modified by thermal treatments. J. Mat. Science. 2016;51:28862901.

8. Maiti BK, Almeida MR, Moura I, Moura JJG. Rubredoxins derivatives: Simple sulphur-rich coordination metal sites and its relevance for biology and chemistry. Coord. Chem. Rev. 2017;352:379-397.

9. Chen Y, Hong S, Fu CW, Hoang T, Li X, Valencia $\mathrm{V}$, et al. Investigation of the Mesoporous MetalOrganic Framework as a New Platform To Study the Transport Phenomena of Biomolecules. ACS Appl. Mater. Interfaces. 2017;9:10874-10881.
10. Xia G, Wang H. Squaraine dyes: The hierarchical synthesis and its application in optical detection, $J$. Photochem. Photobio. C: Photochem. Rev. 2017;31:84-113.

11. Ahmed DS, El-Hiti GA, Hameed AS, Yousif E, Ahmed A. New tetra-Schiff bases as efficient photostabilizers for poly(vinyl chloride). Molecules. 2017;22:1506.

12. Ahmed DS, El-Hiti GA, Yousif E, Hameed AS. Polyphosphates as inhibitors for poly(vinyl Chloride) photodegradation. Molecules. 2017;22:1849.

13. Ghazi D, El-Hiti GA, Yousif E, Ahmed DS, Alotaibi MH. The effect of ultraviolet irradiation on the physicochemical properties of poly(vinyl Chloride) films containing organotin(IV) complexes as photostabilizers. Molecules. 2018;23:254.

14. Shaalan N, Laftah N, Muslih, R, Yousif E. Photostability study of some modified poly(vinyl chloride) containing pendant Schiff's bases. Baghdad Sci. J. 2016;13:188-195.

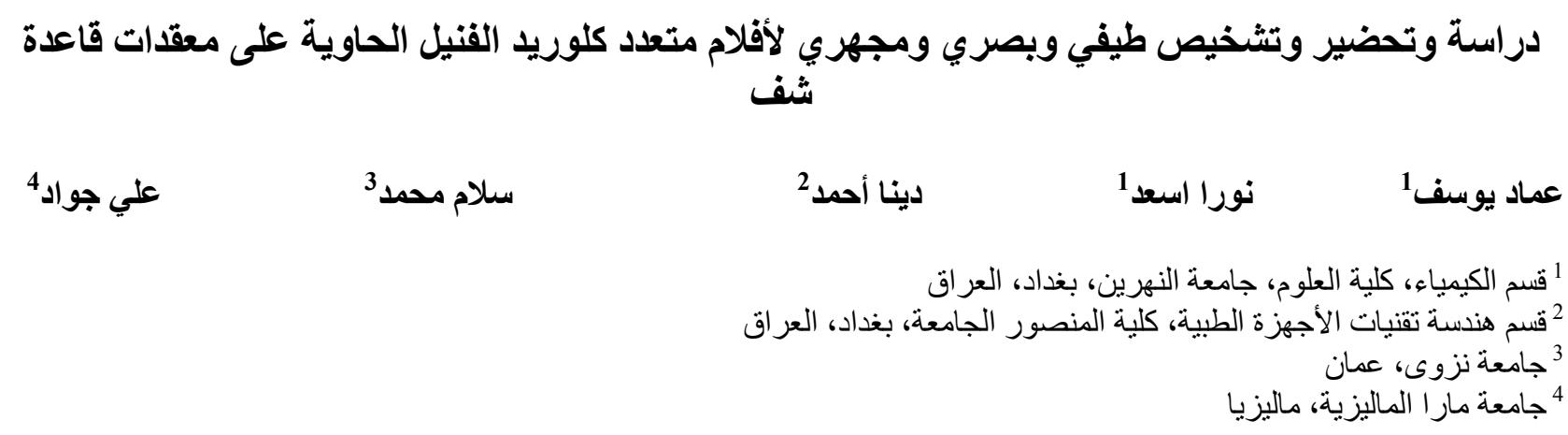

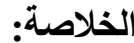

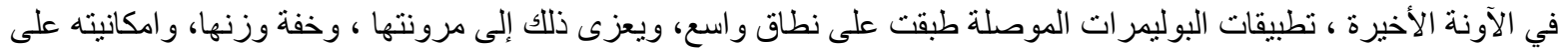

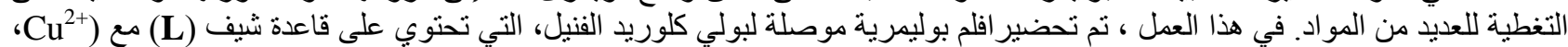
اليولئة

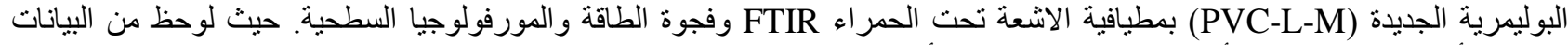

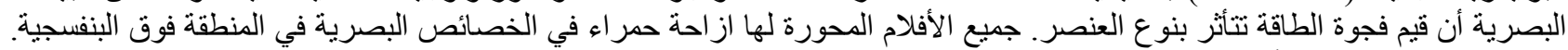

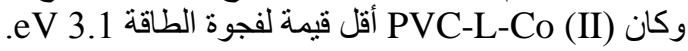

الكلمات المفتاحية: البوليمرات الموصلة، المعقدات الفلزية، الخو اص البصرية، متعدد كلوريد الفينيل، قاعدة شف . 